\title{
Burden of Intestinal Helminth Infection among School Going Children from A South-Asian Nation - Its Implications
}

\author{
NONIKA RAJKUMARI, VENKATACHALAM JAYASEELAM
}

\section{ABSTRACT}

Introduction: Intestinal helminth infections are a problem worldwide in children responsible for a majority of the morbidity associated with it. School going age children are also at special risk of being infected by these parasites.

Aim: To analyse the burden and types of intestinal helminths in school going children in comparison to the whole paediatric population.

Materials and Methods: Five hundred children were included within a period of three years and in all 720 stool and duodenal aspirates samples were collected and sent for routine testing including repeats were included. The study tried to compare the intestinal helminth infections between school going children and preschool children, its distributions, risk factors or any associated morbidities and co-infections.

Results: In all, 127 children were positive for a type of intestinal infection by routine stool/aspirate microscopy which was confirmed by concentration method of which 93 children were positive for an intestinal helminth infection. $24.9 \%(81 / 325)$ of the children were test positive school going children and the remaining 34/127 (26.7\%) children were positive for other non-helminth parasitic infections. Maximum positivity was of hookworm (51, 40.1\%), followed by Strongyloides stercoralis (46, 36.2\%), Ascaris lumbricoides $(21,16.5 \%)$ and Enterobius vermicularis $(9,7 \%)$. Single species of helminth infection was seen in $70.8 \%(90 / 127)$ of the infected children in contrast to $2.3 \%$ (3/127) children having multiple types of parasitic helminth infections. Maximum prevalence was seen among the 6-10 years age group (54.8\%).

Conclusion: Silent infection or hyper infection was seen especially in the immunocompromised children. Intestinal parasitic infections are very much prevalent. Strong suspicion, proper diagnosis and preventive measures are the need of the hour.

\section{Keywords: Epidemiology, Hyperinfection, Silent infection, Soil-transmitted helminths}

\section{INTRODUCTION}

Helminth infections are the most common chronic infections among the school going children of which a major contribution is made by the soil transmitted helminths. Infections due to soil transmitted helminths are most commonly caused by Ascaris lumbricoides, hookworm (Ancylostoma duodenale or Necator americanus and Trichuria trichuri [1]. In the tropical and sub-tropical countries, soil transmitted helminths are among the most common human infections [2,3]. There are over one billion people in this world being affected by soil transmitted helminth's alone [4] particularly putting school age (5-15 years) children at risk [5,3]. An estimated 3.5 billion people are affected with intestinal parasitic infections, of which 450 million belonging to the school going group are ill due to it [6-9]. School going children along with pregnant women are among those in the high risk group [10-12,6]. This in itself poses a huge question on the morbidity and complications associated with it in such children as this problem in mainly seen in economically challenged countries. In such communities, multiparasite infections are also common and there is evidence that individuals harbouring such infections may suffer exacerbated morbidity, of which children are even more vulnerable [13]. Hence, we planned this study to analyse the burden and types of intestinal helminths in school going children in comparison to the whole paediatric population.

\section{MATERIALS AND METHODS}

This cross sectional study was conducted in a tertiary care institute serving as a teaching as well referral center in south India for a period of three years. The data from January 2012 to December 2014 were collected from the parasitology laboratory database and analysed. 


\section{Inclusion Criteria}

All the stool samples and duodenal aspirates which were sent to the Department's parasitology laboratory were screened for the age group and included. All the patients particulars of the included paediatric group encompassing the school going children were collected from the medical record section. For the purpose of this study, school going children were defined as those groups of population belonging to the age group of 6 to 16 years and who were attending school or any form of education at that time [14,2]. Also pre-school children' samples were also screened for comparison.

\section{Exclusion Criteria}

All the stool samples and duodenal aspirates from adults and paediatric population whose age is more than 16 were not taken.

\section{Sample Collection Method}

All the stool samples sent by the clinicians for suspected intestinal helminth infections of children were screened and those of the school going children were taken. Fresh samples were sent in a wide mouthed screw capped container. Repeat samples were asked when the previous sample was positive or strongly suspected for intestinal helminths. All the demographic details were noted along with their clinical history as available.

The samples were processed within 20 minutes after arrival and microscopy done. Routine laboratory method consist of a saline and iodine wet mount of the stool sample to check for any egg/ova, larvae or presence of any adult worms in the stool or duodenal aspirate samples as per standard microbiology methods [15-17]. This was done both for concentrated and un-concentrated stool samples. Routinely, sedimentation technique of concentration method was done supplemented by Zinc sulphate floatation method whenever needed. Repeat samples were asked in those cases where the sample was positive for any of the above mentioned findings to monitor the treatment process or a test negative patient suspected to have intestinal helminth infection. If a child is strongly suspected to have helminth infections but repeated samples shows negative results, then culture of the sample was done for the suspected helminth. Eosinophilia was defined as elevated count of $\geq 0.1 \times 10^{9}$ eosinophils $/ L$ in the peripheral blood for all ages [18].

All the findings including the type of helminth infected, frequency of isolation, the effect of treatment, relation to socio-economic state etc were analysed.

A total of 93 children and 128 samples inclusive of repeat samples were positive for a type of intestinal helminth either as single infection or as co-infection with another helminth or other parasitic infections by concentrated method. However,
$24.9 \%(81 / 325)$ of the children were test positive SGC among the total of 325 school going population enrolled. The remaining of 34 (26.7\%) children was positive for other nonhelminth parasitic infections. Of the total enrolled children, 70 boys and 57 girls showed positive test for stool sample for a type of intestinal parasitic infections; but only 50 boys and 43 girls for intestinal helminth infection. Of these, 180 boys and 145 girls belong to the SGC age group in which 48 boys and 33 girls were positive for the confirmatory intestinal helminth test.

\section{RESULTS}

A total of 500 children were screened for the study, of which $65 \%$ (325) of them belong to the school going age group. From these total children, 720 samples were collected including the repeat samples. In all, 127 children were positive for a type of intestinal infection by routine stool/aspirate microscopy which was confirmed by concentration method. A total of 93 children and 128 samples inclusive of repeat samples were positive for a type of intestinal helminth either as single infection or as co-infection with another helminth or other parasitic infections by concentrated method. However, $24.9 \%(81 / 325)$ of the children were test positive school going children and the remaining 34/127 (26.7\%) children were positive for other non-helminth parasitic infections. Of the total enrolled children, 70 boys and 57 girls showed positive test for stool sample for a type of intestinal parasitic infections; but only 50 boys and 43 girls for intestinal helminth infection. Of these, 180 boys and 145 girls belong to the school going children age group in which 48 boys and 33 girls were positive for the confirmatory intestinal helminth test. The prevalence of overall infection peaked in the age group of $11-16$ years $(56.6 \%, 72)$ followed by the age group of $6-10$ years $(36.2 \%, 46)$ and age group of $0-5$ years $(7 \%$, 9) but the reverse was seen in case of intestinal helminth infection with maximum prevalence among the 6-10 years age group $(54.8 \%, 51)$, followed by $11-16$ years group $(25.8 \%, 24)$ and $0-5$ years group $(19.3 \%, 18)$. Demographic details of the School going children versus Pre- school children are shown in [Table/Fig-1].

Maximum positivity was of hookworm (51, 40.1\%), followed by Strongyloides stercoralis (46, 36.2\%), A. lumbricoides (21, $16.5 \%)$ and Enterobius vermicularis (9, 7\%) in decreasing order of frequency among the school going children. The details and differences in the rate of positivity among various intestinal parasitic helminths are shown in [Table/Fig-2]. Single species of helminth infection was seen in $70.8 \%(90 / 127)$ of the infected children in contrast to $2.3 \%$ (3/127) children having multiple types of parasitic helminth infections.

It was seen that maximum of the patients were from the outpatient department $(83.8 \%, 419)$ compared to the 


\begin{tabular}{|c|c|c|}
\hline Parameters & School going children & Pre-school children \\
\hline Number of children $(n=500)$ & $65 \%(325 / 500)$ & $35 \%(175 / 500)$ \\
\hline Total boys $(n=266)$ & $67.6 \%(180)$ & $32.3 \%(86)$ \\
\hline Total girls $(n=234)$ & $61.9 \%(145)$ & $38 \%(89)$ \\
\hline Total test positive children & $24.9 \%(81 / 325)$ & $6.8 \%(12 / 175)$ \\
\hline Total intestinal helminth positive & $87 \%(81 / 93)$ & $12.9 \%(12 / 93)$ \\
\hline Outpatient $(n=419)$ & $59.6 \%(250)$ & $40.3 \%(169)$ \\
\hline Inpatient $(\mathrm{n}=81)$ & $92.5 \%(75)$ & $7.4 \%(6)$ \\
\hline Presence of co-morbidity (HIV positive/ immunosuppressant/others) & $3.6 \%(18 / 500)$ & $0.8 \%(4 / 500)$ \\
\hline Presence of co-morbidity and intestinal infection & $6.2 \%(8 / 127)$ & $2.3 \%(3 / 127)$ \\
\hline Low Socio-economic status of the included children $(n=500)$ & $48.2 \%(241)$ & $19.4 \%(97)$ \\
\hline Low Socio-economic status among those having intestinal infection $(n=127)$ & $64.5 \%(82)$ & $20.4 \%(26)$ \\
\hline
\end{tabular}

\section{[Table/Fig-1]: Demographic profile of the school going children versus pre-school children.}

\begin{tabular}{|c|c|c|c|c|c|c|c|c|c|}
\hline \multicolumn{2}{|l|}{ Age groups } & \multicolumn{2}{|c|}{ First sample } & \multicolumn{2}{|c|}{ Repeat sample } & \multicolumn{4}{|c|}{ Co-infection } \\
\hline $\begin{array}{l}\text { Type of } \\
\text { intestinal } \\
\text { parasitic } \\
\text { helminth }\end{array}$ & $\begin{array}{l}\text { Form present } \\
\text { in the stool/ } \\
\text { duodenal } \\
\text { aspirate }\end{array}$ & $\begin{array}{c}\text { Routine } \\
\text { Microscopy } \\
\text { of wet } \\
\text { mount }\end{array}$ & $\begin{array}{l}\text { Concentrated } \\
\text { sample } \\
\text { microscopy }\end{array}$ & $\begin{array}{l}\text { Routine } \\
\text { microscopy } \\
\text { of wet } \\
\text { mount }\end{array}$ & $\begin{array}{l}\text { Concentrated } \\
\text { sample } \\
\text { microscopy }\end{array}$ & $\begin{array}{c}\text { Overall } \\
\text { total }\end{array}$ & $\begin{array}{l}\text { With } \\
\text { another } \\
\text { intestinal } \\
\text { helminth }\end{array}$ & $\begin{array}{c}\text { With } \\
\text { another } \\
\text { protozoa }\end{array}$ & $\begin{array}{l}\text { With a } \\
\text { coccidian } \\
\text { parasite }\end{array}$ \\
\hline \multirow{3}{*}{$\begin{array}{l}\text { Strongyloides } \\
\text { stercoralis }\end{array}$} & Larva & 28 & 33 & 11 & 11 & 44 & 3 & 4 & 3 \\
\hline & Egg & 2 & 3 & 0 & 0 & 3 & 0 & 0 & 0 \\
\hline & $\begin{array}{l}\text { Only repeat } \\
\text { sample positive }\end{array}$ & - & - & 1 & 1 & 1 & 0 & 1 & 0 \\
\hline \multirow[t]{4}{*}{ Hookworm } & Egg & 23 & 31 & 10 & 10 & 41 & 0 & 2 & 0 \\
\hline & Larva & 3 & 4 & 2 & 2 & 6 & 0 & 0 & 0 \\
\hline & Adult worm & 0 & 0 & 0 & 0 & 0 & 0 & 0 & 0 \\
\hline & $\begin{array}{l}\text { Only repeat } \\
\text { sample positive }\end{array}$ & - & - & 1 & 2 & 2 & 0 & 0 & 0 \\
\hline \multirow{3}{*}{$\begin{array}{l}\text { Ascaris } \\
\text { lumbricoides }\end{array}$} & Egg & 11 & 13 & 6 & 6 & 19 & 0 & 2 & 0 \\
\hline & Adult worm & 2 & 2 & 0 & 0 & 2 & 0 & 0 & 0 \\
\hline & $\begin{array}{l}\text { Only repeat } \\
\text { sample positive }\end{array}$ & - & - & 1 & 1 & 1 & 0 & 0 & 0 \\
\hline \multirow{3}{*}{$\begin{array}{l}\text { Enterobius } \\
\text { vermicularis }\end{array}$} & Egg & 7 & 7 & 2 & 2 & 9 & 0 & 0 & 0 \\
\hline & Adult worm & 0 & 0 & 0 & 0 & 0 & 0 & 0 & 0 \\
\hline & $\begin{array}{l}\text { Only repeat } \\
\text { sample only }\end{array}$ & - & - & - & & & 0 & 0 & 0 \\
\hline Total & & 76 & 93 & 34 & 35 & 128 & 3 & 9 & 3 \\
\hline
\end{tabular}

[Table/Fig-2]: Distribution of various intestinal parasitic helminth infection among children during the study period.

inpatient department $(16.2 \%, 81)$ indicating that most of the infection are either asymptomatic or the patient is ambulatory. The various clinical complaints presented by the patients include loose motion (44\%), unexplained weight loss (21.2\%), anaemia under evaluation (17.3\%), pain abdomen (8.6\%), intestinal obstruction (5.5\%), immunocompromised state where the patient was found to be human immunodeficiency virus (HIV) positive or on steroids for some medical condition (3.1\%). Patients with the protozoal (68\%)/coccidian infections $(92 \%)$ or co-infections with the intestinal parasitic helminth
(45\%) mostly present with loose motion and pain abdomen whereas those with complaints of anaemia or intestinal obstruction most showed infection with either hookworm (Ancylostoma duodenale or Necator americanus, 86\%) or A. lumbricoides (52\%). Silent infection or hyperinfection was seen in the immunocompromised children. One patient on steroid showed silent infection with $A$. lumbricoides with Giardia lamblia co-infection whereas, 3 children who were HIV positive showed silent but hyperinfection with S. stercoralis. Elevated eosinophil count was seen in $71 \%$ 


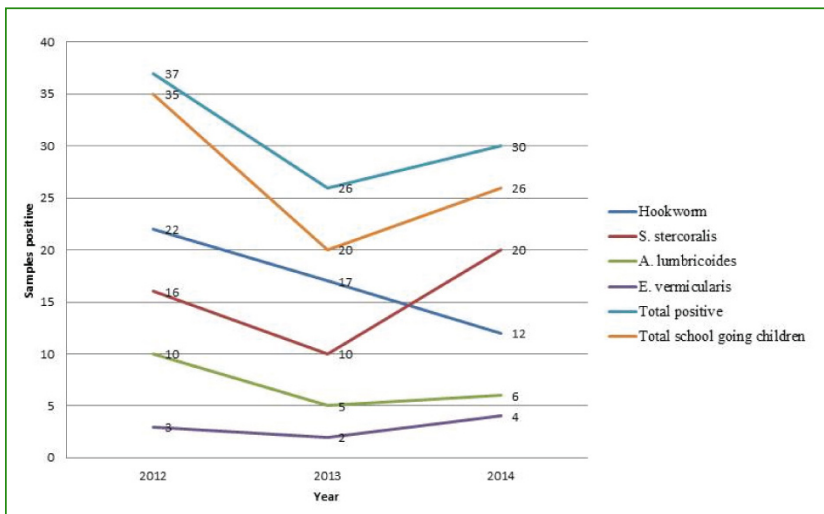

[Table/Fig-3]: Comparative analysis of different intestinal helminths distribution in an annual pattern and comparing total children versus school going children.

of children who were S. stercoralis positive and in $65 \%$ of those who were hookworm positive. It may hence be used as predictor for infection by these intestinal helminths. The treatment response of the parasitic infection either in the form of complete disappearance or decreased count of eggs or larva depends on the initial load of infection. This was supported by the fact that $S$. stercoralis larva or hookworm (A. duodenale or $N$. americanus) eggs were more in the first sample but the repeat sample taken one week later showed a decreased load after starting of treatment. Hookworm eggs were also observed in all stages of maturity.

The study showed that using multiple laboratory methods to examine the stool/duodenal aspirate samples increases the rate of positivity which otherwise would have gone undetected [Table/Fig-2]. Our study showed that infections with other intestinal helminths were increasing compared to the soil transmitted helminths in the annual distribution pattern and hence its burden. The details are shown in [Table/Fig-3].

Ivermectin at a dosage of $200 \mu \mathrm{g} / \mathrm{kg} /$ day orally for 2 days followed by a repeat dose at 14 days in children above 2 years but a dose of $200 \mathrm{mg} /$ day orally for 3 days was given in children less than 2 years to treat uncomplicated S. stercoralis infection with albendazole as alternative. Post treatment stool sample was done to guide the efficacy of the treatment. It was seen that response to ivermectin was better than albendazole. For treatment of hookworm infections, albendazole $(400 \mathrm{mg}$ ) orally once is the treatment of choice in all the age groups, with mebendazole (100mg) twice daily orally for 3 days as an alternative. A repeat dose was usually given to achieve complete and high cure rate. Similarly, albendazole (400mg orally, single dose) was also used to treat ascariasis which serves the dual purpose of treating co-infection of hookworm infection with $A$. lumbricoides infection with a single drug. Same drug at a dose of $400 \mathrm{mg}$ orally as single dose was used to treat $E$. vermicularis with a repeat dose after two weeks.
The remaining 34 children who tested positive for nonhelminth infections (a total of 25 were positive for non helminths infections among SGC and the remaining was seen in PSC) showed infections ranging from Entamoeba histolytica (trophozoites/cysts, $n=20$ ), Blastocystis hominis (vacuolar form/cysts, $n=6$ ), Giardia lamblia (trophozoites/ cysts, $n=3$ ), Balantidium coli (trophozoites, $n=1$ ), or the coccidian opportunistic parasites. The coccidian parasites which were frequently isolated were Cystoisospora belli (oocysts, $\mathrm{n}=6$ ) and Cryptosporidium parvum (oocysts, $\mathrm{n}=$ 2) especially in those children who were HIV positive or were immunocompromised due to other conditions. The most common co-infection was with E. histolytica $(\mathrm{n}=2)$, followed by $B$. hominis $(n=2)$. E. histolytica was also seen as the most common co-infection with an intestinal helminth followed by Giardia sp. All these non-helminth intestinal parasitic infections either occurred as isolated infection $(n=32)$ or as co-infections $(n=2)$.

Among the 127 children who tested positive for an intestinal infection, 110 (86.6\%) belong to the lower socio-economic strata where the children's parents were mostly manual laborers, farmers, daily wagers etc. Simultaneous testing of the parents also showed that one of the parents was infected with an intestinal helminth in 68\% (63/93) of the intestinal helminth positive children whereas both the parents were infected with intestinal helminth in 12\% (11/93) cases.

\section{DISCUSSION}

The clinical significance of the study is that routine screening of stool samples should be done as silent infections are common. Also, multiple samples and diagnostic methods should be used to catch the missed out cases which will help in timely diagnosis and treatment and hence, decrease its burden and morbidity. The type of intestinal helminth burden is different from other parts of the world and also other parts of the country which will enable us to plan the treatment and preventive methods differently.

Our study showed that rate of other intestinal parasitic infections was more compared to the soil transmitted helminths in the children which was in contrast to the finding of other study $[19,20]$. Hookworm (A. duodenale and $N$. americanus) was responsible for maximum infections in all the children irrespective of the age group at the beginning of the study but it was slowly exceeded by $S$. stercoralis by the end of the study as shown in [Table/Fig-3]. This was in contrast to other studies where most common cause of infection were A. lumbricoides, [19] or Ascaris sp. and hookworm was highest in school going children, [20,2] or E. vermicularis (18\%), [1] or Hymenolypis nana (5.6\%) [20] in children. A total of $72 \%$ were asymptomatic and had come to the hospital for other causes thereby indicating the silent burden of intestinal 
helminths in children of south India. There were also coinfections of helminthiasis and intestinal protozoa. The most common co-infection was with $E$. histolytica $(n=2)$, followed by $B$. hominis $(\mathrm{n}=2)$. E. histolytica was also seen as the most common co-infection with an intestinal helminth followed by Giardia species in another study [21]. E. histolytica $(n=20)$ was also maximally isolated even without an intestinal parasitic helminth too in our study, similar to another study [19]. However, the most common coccidian parasite seen in our study was $C$. belli $(n=6)$ followed by $C$. parvum in the co-infections with intestinal helminths and seen mostly in immunocompromised patients.

Age-specific prevalence data show a relationship between age and prevalence of parasites. In our study, the prevalence of infection peaked in the age group of $11-16$ years $(56.6 \%$, 72) followed by the age group of $6-10$ years $(36.2 \%, 46)$ and age group of $0-5$ years $(7 \%, 9)$ but the reverse was seen in case of intestinal helminth infection with maximum prevalence among the 6-10 years age group (54.8\%, 51), followed by $11-16$ years group $(25.8 \%, 24)$ and $0-5$ years group $(19.3 \%, 18)$. It was in contrast to the findings in another study where the maximum prevalence of $84.91 \%$, was seen in the $11-15$ age group followed by $81.70 \%$ in the $6-10$ age group, and $50.54 \%$ in the $1-5 y r$ age group $[22,19]$. There was no significant difference in the risk involved in the gender; though the infection was more in male $(n=266)$ compared to female children ( $n=234)$. This finding was supported by other studies $[23,19]$.

Post treatment stool sampling can guide the efficacy of the treatment and our study also showed that 31 repeat samples were positive after the first positive sample. Muller et al., also showed a similar observation [24]. Hence, repeat sampling was very much essential for guiding the treatment efficacy which otherwise would have gone as incomplete cure and would have added to the helminth burden of the children population. Not only this, multiple sampling also increases the rate of positivity. In our study, four samples came positive only in repeat samples but were negative in the first sample. Hence, multiple samples must be recommended in children especially in high risk children or immunocompromised children. Silent infections were very common in such children which may pose a risk of serious complications later on. This was highlighted by the hyperinfection of $S$. stercoralis in immunocompromised patients.

The current study showed that soil transmitted helminth infections were slowly decreasing compared to other types of parasitic intestinal helminths. A study by Macchioni et al., supported this finding [20]. This might be due to the preventive chemotherapy like mass deworming of school going children. Also, intensified health education and improved sanitation should be done to control protozoan infections which were seen in high rate in these children.

\section{LIMITATIONS}

Being a retrospective study, more details regarding the clinical details cannot be obtained and long term follow-up was also not possible. Here, only one week follow up which is usually followed as a part of the hospital protocol was noted as it was recorded in the case sheets and hospital informatics database. Also, more details on the familiar infections could not be taken in detail. Some of the school going children sample had to be removed from analysis as there were no repeat samples.

\section{CONCLUSION}

Intestinal parasitic helminths are very much prevalent in children especially in school going children; though the rate of infection by soil transmitted helminths are slowly decreasing. Proper diagnosis and prevention is the need of the hour.

\section{REFERENCES}

[1] Salim N, Schindler T, Abdul U, Rothen J, Genton B, Lweno $\mathrm{O}$, Mohammed AS, et al. Enterobiasis and strongyloidiasis and associated co-infections and morbidity markers in infants, preschool- and school-aged children from rural coastal Tanzania: a cross-sectional study. BMC Infec Dis. 2014;14:644.

[2] Kattula D, Sarkar R, Rao Ajjampur SS, Minz S, Levecke B, Muliyil $J$, et al. Prevalence \& risk factors for soil transmitted helminth infection among school children in south India. Indian J Med Res. 2014;139(1):76-82.

[3] Debalke S, Worku A, Jahur N, Mekonnen Z. Soil transmitted helminths and associated factors among school children in government and private primary school in Jimma Town, Southwest Ethiopia. Ethiop J Health Sci. 2013;23(3):237-44.

[4] Crompton DW. How much human helminthiasis is there in the world? J Parasitol. 1999; 85: 397-403.

[5] WHO, Prevention and control of schistosomiasis and soil transmitted Helminthiasis. Report of a WHO Expert Committee. 2002; Technical Report Series, No 912. pp. 63 Geneva, World Health Organization.

[6] Tulu B, Taye S, Amsalu E. Prevalence and its associated risk factors of intestinal parasitic infections among Yadot primary school children of South Eastern Ethopia: a cross sectional study. BMC Research Notes. 2014;7:848.

[7] Ayalew A, Debebe T, Worku A. Prevelance and risk factors of intestinal parasites among Delgi school children, North Gondar, Ethiopia. J Parasitol Vector Biology. 2011;3(5):75-81.

[8] Mangistu A, Gebre-Selassie S, Kassa T. Prevalence of intestinal parasitic infections among urban dwellers in southwest Ethiopia. Ethiop J Health Dev. 2007;21(1):12-17.

[9] Okyay P, Ertug S, Gultekin B, Onen O, Beser E. Intestinal parasites prevalence and related factors in school children, a western city sample - Turkey. BMC Public Health. 2004;4:6469.

[10] Matthys B, Bobieva M, Karimova G, Mengliboeva Z, JeanRichard V, Hoimnazarova $\mathrm{M}$ et al. Prevalence and risk factors of helminths and intestinal protozoa infections among children from primary schools in western Tajikistan. Parasites Vectors. 2011;4:195-208. 
[11] Bankae ROK, Omudu EA, Ikenwa DA, Feese U. Prevalence of gastro-intestinal parasites in relation to availability of sanitary facilities among schooling children in Makurdi, Nigeria. Anim Res Int. 2006;3(2):489-93.

[12] Ai-Mohammed HI, Amin TT, Aboulmagd E, Hablus HR, Zaza BO, Al-Mohammed $\mathrm{HI}$. Prevalence of intestinal parasitic infections and its relationship with socio-demographics and hygienic habits among male primary schoolchildren in Al-Ahsa, Saudi Arabia. Asian Pac J Trop Med. 2010;3(11):906-12.

[13] Drake LJ, Bundy DA. Multiple helminth infections in children: impact and control. Parasitology. 2001;122 Suppl:S73-81.

[14] Sayeemuddin $M$, Sharma D, Pandita A, Sultana T, Shastri $\mathrm{S}$. Blood pressure profile in school children (6-16years) of southern India: a prospective observational study. Front Pediatr. 2015;3:24

[15] Bench Aids for the diagnosis of intestinal parasitic infections. WHO: Geneva.2012.

[16] Montresor A, Crompton DWT, Gyorkos TW, Savioli L. Helminth control in school age children. Geneva: World Health Organization. 2002.

[17] Garcia LS. Diagnostic Medical parasitology. American Society for Microbiology Press. NW, Washington DC, USA 2009. $5^{\text {th }}$ Edn.

[18] Orkin HS, Fisher ED, Look AT, Lux IVS, Ginsburg D, Nathan GD. Nathan and Oski's Hematology of infancy and childhood. Philadelphia; London: Saunders 2009, $7^{\text {th }}$ edn.

\section{AUTHOR(S):}

1. Dr. Nonika Rajkumari

2. Dr. Venkatachalam Jayaseelam

\section{PARTICULARS OF CONTRIBUTORS:}

1. Assistant Professor, Department of Microbiology, Jawaharlal Institute of Postgraduate Medical Education and Research, Puducherry, India.

2. Assistant Professor, Department of Preventive and Social Medicine, Jawaharlal Institute of Postgraduate Medical Education and Research, Puducherry, India.
[19] Wani SA, Agmad F, Zargar SA, Amin A, Dar ZA, Dar PA. Intestinal helminthiasis in children of Gurez Valley of Jammu and Kashmir State, India. J Glob Infect Dis. 2010; 2(2): 91-94.

[20] Macchioni F, Segundo H, Gabrielli S, Totino V, Gonzales PR, Salazar E, et al. Dramatic decrease in prevalence of soiltransmitted helminths and new insights into intestinal protozoa in children living in the Chaco region, Bolivia. Am J Trop Med Hyg. 2015;92(4):794-96.

[21] Lee SC, Ngui R, Tan TK, Muhammad Aidil R, Lim YA. Neglected tropical diseases among two indigenous subtribes in peninsular Malaysia: highlighting differences and co-infection of helminthiasis and sarcocystosis. PLoS One. 2014; 9(9):e107980.

[22] Ibrahim $\mathrm{AH}$. Prevalence of intestinal parasites among school children in Dier-El-Balah town in Gaza, Strip, Palestine. Ann Saudi Med. 2002; 22:273-75.

[23] Singh DS, Hotchendani RK, Kumar S, Seecatt JS, Srivastava PK, Udupa KN. Prevalence and pattern of intestinal parasitism, arural community of Varanasi. Indian $J$ PrevSoc Med. 1984;15:01-08.

[24] Müller A, Fätkenheuer G, Salzberger B, Schrappe M, Diehl V, Franzen C. Strongyloides stercoralis infection in a patient with AIDS and non-Hodgkin lymphoma. Dtsch Med Wochenschr. 1998;123(13):381-85.

\section{NAME, ADDRESS, E-MAIL ID OF THE CORRESPONDING AUTHOR:}

Dr. Nonika Rajkumari, Assistant Professor, Department of Microbiology, $2^{\text {nd }}$ Floor, Institute Block, Jawaharlal Institute of Postgraduate Medical Education and Research, Puducherry-605006, India. E-mail: nonika.raj@gmail.com

FINANCIAL OR OTHER COMPETING INTERESTS: None.

Date of Publishing: Apr 01, 2016 